Journal of Social

Transformation and

Regional

Development

\title{
Intention to Use Humanoid Robotic as Assistive Rehabilitation Treatment for Children with Autism
}

\author{
Amily Fikry ${ }^{1 *}$, Hamizah Hassan ${ }^{2}$ \\ ${ }^{1}$ Department of Marketing, Retailing and Entrepreneurship, \\ Faculty of Business and Management, Universiti Teknologi MARA, Shah Alam, Selangor Darul Ehsan, \\ Malaysia. \\ ${ }^{2}$ Department of Economics and Finance Studies, \\ Faculty of Business and Management, Universiti Teknologi MARA, Shah Alam, Selangor Darul Ehsan, \\ Malaysia.
}

DOI: https://doi.org/10.30880/jstard.2019.01.01.004

Received January 2019; Accepted April 2019; Available online June 2019

\begin{abstract}
Researchers have found that humanoid robotic can be an assistive rehabilitation treatment for Autism children. This paper aims to discover the awareness and the intention of rehab managers to use it at their rehab centers in Malaysia. Two (2) public rehabilitation centers located in the Northern Region of Peninsular Malaysia were selected and two managers and four assistants in each center were interviewed by employing an in-depth interview (IDI) method. The study found that majority of rehab managers and their assistant lack of awareness but intent to use humanoid robotic as an assistive rehabilitation treatment for Autism children at their centers. The findings of this study can aid responsible parties in planning for the public rehab centers to start using humanoid robotic for autism children as an assistive rehabilitation treatment.
\end{abstract}

Keywords: assistive rehabilitation treatment; autism spectrum disorder; children; humanoid robotic; rehab center.

\section{Introduction}

Autism Spectrum Disorder (ASD) is a developmental disorder that encompasses varieties of disorder with impairments in social relationships, communication, and imaginative play (Shamsudin et al., 2012) and with the severity and nature of the symptoms varying from one individual to another. With early intervention, quality of life of children with Autism can be improved. Several types of treatment including drugs (Lonsdale, Shamberger \& Audhya, 2002) and non-drugs treatment (such as speech therapy and visual schedules) (Green et al., 2006) have been attempted over the years but to no avail due to nature of disorder and large variations in symptoms. No single approach works best for to reduce symptoms of children with Autism. One therapy may work well with one child may not work well with others (Cabibihan et al., 2013).

Although no single best therapy works for all children with Autism, there is still a need to treat these children. By involving in early intervention programs, it will help autistic children to improve from their autistic 
disabilities by being almost like other normal children (Sitimin et al., 2014). The earlier the treatment received by children with Autism, the better it will be for their growth development.

\section{Humanoid Robotic as Assistive Rehabilitation Treatment}

The use of robot technology as an early intervention for children with Autism has greatly increased over the years. Some robots used are humanoids, while others are small, mobile and carlike (non-humanoids). Nonhumanoid robots may be in the form of animals, cars and toys; have been used by various researchers due to its affordability, simplicity and ease of capturing attention (Ricks and Colton, 2010). However, this nonhumanoid robotics offers a very small interaction with the Autism child (Dautenhahn and Billard, 2002). These types of robots serve the function it requires but may not be beautifully designed.

On the other hand, the use of humanoid robotic (human form of robot) in autism therapy are able to complement the drawbacks of non-humanoid robots (Dautenhahn and Billard, 2002). Humanoid robotics have the ability to engage children in imitation and recognition activities [Ricks and Colton, 2010] and assist in interaction between Autism children and the humanoid robotic itself (Shamsudin et al., 2012; Robins et al., 2009).

Noting that humanoid robotic is part of early intervention of assistive rehabilitation treatment for children with Autism, in this paper, researcher tends to explore rehab managers awareness and intention to use humanoid robotic for children with Autism at their centre.

\section{Methods}

An in-depth interview (IDI), semi structured with open-ended questions were used to obtain free expression of the views on awareness and intention to use humanoid robotic as assistive rehabilitation treatment for children with Autism in the selected rehab centre. The interviews were conducted with 2 managers and 4 assistant from 2 rehabilitation centre in Northern Region of Peninsular Malaysia. The interviewee were being selected based on their nature of job i.e. as managers and assistant at the rehab center, where they are the person who have direct contact with children with Autism and knows best what the Autism children needs the most.

The questions used in IDI were self-developed. The list of questions were as shown below:

Question 1: Are you aware of the use of humanoid robotic as assistive treatment for children with Autism?

Question 2: Do you intent to use humanoid robotic for Autism children in your rehab centre?

Question 3: What types of treatment is suitable to be used using humanoid robotic?

\subsection{Rehab centre selected}

In Malaysia, the rehab center can be categorized as private rehab center and public (government assisted) rehab center. As such, for this research, the 2 public rehab center (being called as Pemulihan Dalam Komuniti) selected are located in Northern Region. These rehab center are being assisted and monitored by Department of Social Welfare with each rehab center is being managed by rehab manager. The public rehab center accepts all special needs people in various age with all types of impairment who have registered with Department of Social Welfare and obtain special needs card (Orang Kelainan Upaya card).

\subsection{Interview Questions}

The semi-structured with open ended interview questions that covered on awareness and intention to use humanoid robotic as parts of assistive rehabilitation treatment, and suggestion on types of treatment for humanoid robotic were asked to 2 managers and 4 assistant of rehab center. Noting that qualitative research is an iterative process and researcher had different types of interviewees, the questions wording changed slightly in relation to the interviewee response towards the interview questions. 


\section{Discussion}

This section will provide discussion on findings based on the interview conducted with two (2) managers and four (4) assistant of rehabilitation centre.

\subsection{Demographic profile of the interview participants.}

From the IDI, it was found that majority of the interviewees of rehab center are of female gender (66.67\%) and holds position as assistant $(66.67 \%)$ in the rehab center, as shown in Table 1 below:

Table 1 - Demographic profile of the interviewee.

\begin{tabular}{lcc}
\hline Gender & Frequency & Percentage (\%) \\
\hline Male & 2 & 33.33 \\
Female & 4 & 66.67 \\
Total & 6 & $100 \%$ \\
& & \\
\hline Job Position & & \\
Manager & 2 & 33.33 \\
Employee & 4 & 66.67 \\
Total & 6 & $100 \%$ \\
\hline
\end{tabular}

\subsection{Awareness and intention to use humanoid robotic for children with Autism at the rehab center.}

There are three (3) main questions were asked to the interview participants, covered on awareness, intention and types of treatment suggested to be used as part of the rehab treatment for children with Autism. The findings of the interview are as follows:

\subsubsection{Question 1: Are you aware of the use of humanoid robotic as assistive treatment for children with Autism?}

From the IDI, it was found that majority of the interview participants (66.67\% of interview participant) are not aware of the use of humanoid robotic as part of assistive treatment for the children with Autism (as depicted in Figure 1).

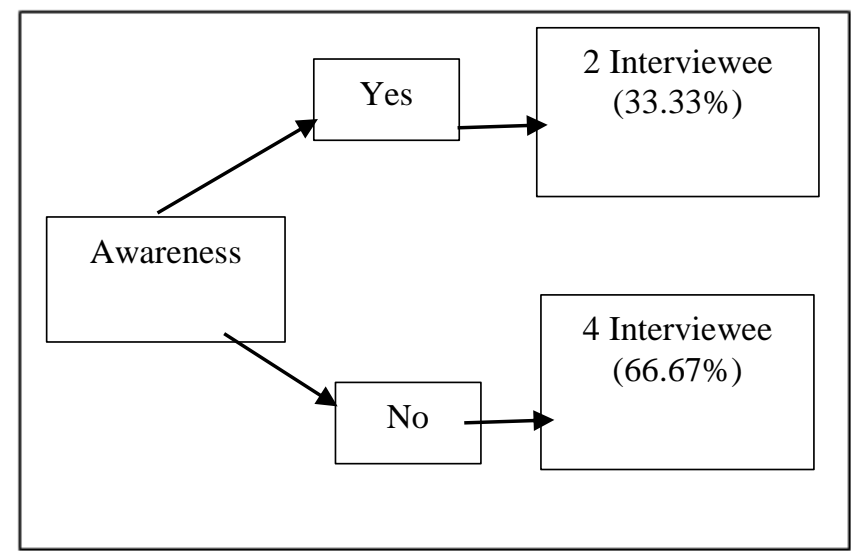

Fig. 1 - Interviewee awareness on using humanoid robotic as assistive treatment for children with Autism. 
Noting that the rehab centre are located in Northern region where technology awareness is low as compared to central region, thus the lack of awareness of humanoid robotic is expected. This is in line with the report published by Malaysian Communication and Multimedia Commission (2017).

\subsubsection{Question 2: Do you intent to use humanoid robotic for Autism children in your rehab centre?}

Even though majority of the rehab center manager are not aware of humanoid robotic as assistive treatment for children with Autism, they shows interest and intent to use humanoid robotic as part of assistive rehab treatment for the Autistic children at their centre. Albeit slightly different with the study of (Fridin and Belokopytov, 2014) that focuses on education industry, but part of the treatment is similar especially in terms of using robotic to enhance interactive skills among children with Autism.

However, they highlight several concerns pertaining to the use of humanoid robotic at the rehab centre. Majority of them concern on the cost of purchasing and maintaining the humanoid robotic, availability of training to their staff and durability of the usage of humanoid robotic for Autism children. This is because, during the treatment process, children with Autism may attempt to damage the humanoid robotic.

\subsubsection{Question 3: What types of treatment is suitable to be used using humanoid robotic?}

The rehab managers feels that it is suitable to use humanoid robotic as part of occupational therapy and social skills development. The proposition made by rehab managers is in line with the findings of (Robins et al., 2005; Billard et al., 2006).

However, the rehab managers further highlighted that the use of humanoid robotic for children with Autism need to be assisted by trained or skilled teacher. This is because all the rehab centre managers covered for this study have not been exposed to the use of humanoid robotic as part of the rehab treatment for children with Autism at their centre. More treatment may be suggested by rehab managers if they are being exposed to humanoid robotic, due to more realization of the benefits gained by the robotic itself (Kim, Park and Sundar, 2013; Moro et al., 2018). The suggestion made by rehab managers is in line with the study of (Cabibihan et al., 2013) but against the findings of (Feil-Seifer and M.J.M., 2005) which indicate that the social assistive robotic system requires no expert operator or extensive training to use it.

\section{Conclusion}

There is a lack of awareness in using humanoid robotic as an alternative treatment for autism children at the public rehab centers in the Northern Region of Peninsular Malaysia. Nonetheless, both rehab managers and their assistant strongly believe that the usage of the humanoid robotic can benefited the autism children and they are interested to use it with certain constraints in mind such as the cost of the humanoid and the skills needed by the teachers to operate it. As such, this study made an important contribution for the government as well as non-government organizations to assist and give full support to the public rehab centers in using humanoid robotic as a treatment for autism children in Malaysia.

\section{Acknowledgement (Acknowledgement)}

The researchers would like to acknowledge the Ministry of Education Malaysia (MOE) for the fund received through the Niche Research Grant Scheme (NRGS), [Project File: 600-RMI/NRGS 5/3 (14/2013)] and Department of Social Welfare for the supports given throughout this research.

\section{References}

Billard, A., Robins, B., Nadel, J., \& Dautenhahn, K. (2006). Building Robota, a Mini-Humanoid Robot for the Rehabilitation of Children with Autism. RESNA Assistive Technology Journal. 
Cabibihan, J.-J., Javed, H., Jr., M. A., \& Aljunied, S. M. (2013). Why robots? A survey on the roles and benefits of social robots in the therapy of children with autism. International Journal of Social Robotics, 5(4), 593-618.

Dautenhahn, K., \& Billard, A. (2002). Games Children with Autism Can Play With Robota, a Humanoid Robotic Doll. Paper presented at the Proceeding 1st Cambridge Workshop on Universal Access and Assistive Technology (CWUAAT). In: S Keates, PJ Clarkson, PM Langdon and P Robinson (eds.) Universal Access and Assistive Technology.

Feil-Seifer, D., \&', M. J. M. (2005). Defining Socially Assistive Robotics. Paper presented at the Proceedings of the 2005 IEEE 9th International Conference on Rehabilitation Robotics Chicago,Illinois, USA.

Fridin, M., \& Belokopytov, M. (2014). Acceptance of socially assistive humanoid robot by preschool and elementary school teachers. Computers in Human Behavior, 33, 23-31.

Green, V. A., Pituch, K. A., Itchon, J., Choi, A., O’Reilly, M., \& Sigafoos, J. (2006). Internet survey of treatments used by parents of children with autism. Research in Developmental Disabilities, 27, 70-84.

Kim, K. J., Park, E., \& Sundar, S. S. (2013). Caregiving role in human-robot interaction: A study of the mediating effects of perceived benefit and social presence. Computers in Human Behavior, 29, 1799-1806.

Lonsdale, D., Shamberger, R. J., \& Audhya, T. (2002). Treatment of autism spectrum children with thiamine tetrahydrofurfuryl disulfide: A pilot study. Neuroendocrinology Letters, 23, pp.303-308.

Malaysian Communication and Multimedia Commission: 'Internet Users Survey 2017', in Editor: 'Book Internet Users Survey 2017' (Malaysian Communications and Multimedia Commision, 2017)

Moro, C., Lin, S., Nejat, G., \& Mihailidis, A. (2018). Social Robots and Seniors: A Comparative Study on the Influence of Dynamic Social Features on Human-Robot Interaction. International Journal of Social Robotics, 1-20.

Ricks, D. J., \& Colton, M. B. (2010). Trends and Considerations in Robot-Assissted Autism Therapy. Paper presented at the Proceedings - IEEE International Conference on Robotics and Automation.

Robins, B., Dautenhahn, K., Boekhorst, R. t., \& Billard, A. (2005). Robotic Assistants in Therapy and Education of Children with Autism: Can a Small Humanoid Robot Help Encourage Social Interaction Skills? International Journal Universal Access in the Information Society, 1-21.

Robins, B., Dautenhahn, K., \& Dickerson, P. (2009). From Isolation to Communication: A Case Study Evaluation of Robot Assisted Play for Children with Autism with a Minimally Expressive Humanoid Robot. Paper presented at the 2009 Second International Conferences on Advances in Computer-Human Interactions, Cancun, Mexico.

Shamsudin, S., Yussof, H., Ismail, L., Hanapiah, F. A., Mohamed, S., \& Piah, H. A. (2012). Initial Response of Autistic Children in Human-Robot Interaction Therapy with Humanoid Robot NAO. Paper presented at the 2012 IEEE 8th International Colloquium on Signal Processing and its Applications.

Sitimin, S. A., Ismail, Z., Fikry, A., Hassan, H., Ahmad, S. S., Samat, N., . Hashim, R. (2014). A review on employee benefits for working parents with autistic children. Paper presented at the 2014 IEEE International Symposium on Robotics and Manufacturing Automation (ROMA). 